\title{
Diagnostic value of fine-needle aspiration biopsy for breast mass: a systematic review and meta-analysis
}

\author{
Ying-Hua Yu, Wei Wei and Jian-Lun Liu*
}

\begin{abstract}
Background: Fine-needle aspiration biopsy (FNAB) of the breast is a minimally invasive yet maximally diagnostic method. However, the clinical use of FNAB has been questioned. The purpose of our study was to establish the overall value of FNAC in the diagnosis of breast lesions.

Methods: After a review and quality assessment of 46 studies, sensitivity, specificity and other measures of accuracy of FNAB for evaluating breast lesions were pooled using random-effects models. Summary receiver operating characteristic curves were used to summarize overall accuracy. The sensitivity and specificity for the studies data (included unsatisfactory samples) and underestimation rate of unsatisfactory samples were also calculated.
\end{abstract}

Results: The summary estimates for FNAB in diagnosis of breast carcinoma were as follows (unsatisfactory samples was temporarily exluded): sensitivity, 0.927 (95\% confidence interval [Cl], 0.921 to 0.933 ); specificity, 0.948 ( $95 \% \mathrm{Cl}$, 0.943 to 0.952 ); positive likelihood ratio, 25.72 ( $95 \% \mathrm{Cl}, 17.35$ to 28.13 ); negative likelihood ratio, 0.08 ( $95 \% \mathrm{Cl}, 0.06$ to 0.11 ); diagnostic odds ratio, 429.73 ( $95 \% \mathrm{Cl}, 241.75$ to 763.87$)$; The pooled sensitivity and specificity for 11 studies, which reported unsatisfactory samples (unsatisfactory samples was considered to be positive in this classification) were $0.920(95 \% \mathrm{Cl}, 0.906$ to 0.933$)$ and 0.768 ( $95 \% \mathrm{Cl}, 0.751$ to 0.784$)$ respectively. The pooled proportion of unsatisfactory samples that were subsequently upgraded to various grade cancers was $27.5 \%$ (95\% $\mathrm{Cl}, 0.221$ to 0.296$)$.

Conclusions: FNAB is an accurate biopsy for evaluating breast malignancy if rigorous criteria are used. With regard to unsatisfactory samples, futher invasive procedures are required in order to minimize the chance of a missed diagnosis of breast cancer.

\section{Introduction}

Palpable breast mass is a common problem in female patients. The diagnostic delays of breast cancer occur due to the generally low index of suspicion. The traditional diagnosis mode of breast mass is excisional biopsy, which gives a precise diagnosis but may yield a benign pathological result in most cases.

Fine-needle aspiration biopsy (FNAB) of the breast is a minimally invasive diagnostic method, often obviating an open biopsy [1]. It is cheaper to perform and its results can be available within a shorter time. However, the role

\footnotetext{
* Correspondence: jianlunliu@hotmail.com

Departmant of Breast Surgery of Guangxi Cancer Hospital \& Affiliated Cancer Hospital of Guangxi Medical University, Nanning 530021, Guangxi, P.R.China
}

of FNAB has been challenged of late by better overall results attained by core biopsies. Core biopsy is definitely a robust and reliable diagnostic modality, but carries disadvantages in terms of a longer turn-around due to the tissue processing time, and patient discomfort during the procedure. FNAB has some advantages over core-needle biopsy in that it use a smaller needle and thus has a lower probability of causing hematoma and other rare complications, such as pneumothorax [2,3]

With the introduction of stereotactic and ultrasonographically (US) guided methods for nonpalpable lesions, fine-needle aspiration biopsy (FNAB) have been used more widely in the evaluation of nonpalpable breast lesions [4-6]. Furthermore, the triple-diagnostic method (consisting of clinical evaluation, mammography and
C Biomed Central

(C) 2012 Yu et al; licensee BioMed Central Ltd. This is an Open Access article distributed under the terms of the Creative Commons Attribution License (http://creativecommons.org/licenses/by/2.0), which permits unrestricted use, distribution, and reproduction in any medium, provided the original work is properly cited. 
FNAB) gives a precise diagnosis and reduces the risk of missed diagnosis of breast cancer to < 1\% [7].

However, the clinical use of FNAB has been questioned because of the variability in results reported [8] In addition, It is also possible that no cells are harvested making cytological analysis impossible. Many institutes in the United Kingdom, the United States and Canada have now abandoned FNA for diagnosis of breast lesions. Nevertheless, it continues to be used in other institutes in these countries, as well as in Greece, Italy, Australia and Japan, and in developing countries such as India, Pakistan, Nigeria, Mexico and Thailand. Up to now, there was no meta-analysis to establish the overall value of FNAB for the diagnostic breast cancer. The purpose of our study was to establish the overall value of FNAC in the diagnosis of breast lesions.

\section{Materials and methods}

Search strategy and study selection

We searched MEDLINE (1966 to 2010), EMBASE (1970 to 2010), the Cochrane Central Register of Controlled Trials (CENTRAL), database of Health Technology Assessments on The Cochrane Library issue 2, 2010 and the China Biological Medicine Database (CBM-disc, 1979 to 2010), VIP Chinese Journals Database (1968 to 2010), China National Knowledge Infrastructure Whole Article Database (CNKI, 1994 to 2010). We also searched the trials registers of Cochrane Breast Cancer Group and the WHO International Clinical Trials Registry at http://www. who.int/ictrp/en/ for ongoing and recently completed trials. All searches were up to date as of December 2010. The search terms used were "breast neoplasms", "fine-needle aspiration biopsy", "Sensitivity and Specificity" and "accuracy". In addition, related keywords and their synonyms were included in our search strategy and reference lists were scanned for additional publications. In order to form a highly sensitive search strategy, there were no restrictions on publication status, or study design. Although no language restrictions were imposed initially, for the full-text review and final analysis, our resources only permitted the review of articles published in the English and Chinese language. Letters, conference abstracts and grey literature to the journal editors were excluded because of the limited data presented.

From the studies obtained in the above search, only those meeting the following criteria were qualified for subsequent analyses: Chinese and English languages, any study designed with at least thirty patients, reporting allcomers populations with suspicious breast lesion after clinic screening. The index biopsy method is fine-needle aspiration biopsy (FNAB) with or without image-guide. Two reviewers (Yinghua Yu, Wei Wei) selected eligible studies independently. Discrepancies were solved by discussion.

\section{Data extraction and quality assessment}

Data extraction was performed independently by two reviewers (Yinghua Yu, Wei Wei)). The two reviewers were blinded to publication details, and all extracted data had to be agreed upon by them. Data retrieved from the reports including study design, participant characteristics, lesion size, FNAB procedures, outcomes measurement, publication year, and methodological quality. The numbers of true-positive, false-positive, false-negative, and true-negative results are displayed for each study in Table 1.

We assessed the methodological quality of the studies using guidelines published by the quality assessment for studies of diagnostic accuracy (QUADAS) tool [9] [i.e. appraisal by use of empirical evidence, expert opinion, and formal consensus to assess the quality of primary studies of diagnostic accuracy]. In addition, for each study the following characteristics of study design were also retrieved: (1) needle gauge (21 gauge vs other size gauge); (2) guidance systems (with ultrasound or stereotactic guidance vs without image guidance); (3) prospective data collection, and (4) geographic location; (5) reference standard (histopathology only or not). If no data on the above criteria were reported in the primary studies, we requested the information from the authors. If the authors did not respond to our letters, the "unknown" items were treated as "no."

\section{Statistical analysis}

We used standard methods recommended for meta-analyses of diagnostic test evaluations [10]. Analyses were performed using RevMan5 software (the Cochrane Information Management System (IMS)), STATA version 10.0 (STATA Corporation, TX, USA) and Meta-DiSc (for Windows; XI Cochrane Colloquium; Barcelona, Spain).

We categorized the cytological results according to The National Cancer Institute recommendation for the diagnosis of breast aspiration cytology:

- $\mathrm{Cl}=$ unsatisfactory.

- $\mathrm{C} 2$ = cells present all benign; no suspicious features.

- $\mathrm{C} 3$ = cells suspicious but probably benign.

- $\mathrm{C} 4$ = cells suspicious but probably malignant.

- C5 = Definitely malignant.

This category' is used when the degree of diagnostic certainty is such that the pathologist would be happy for the patient to undergo major breast surgery on the basis of the cytology sample alone.

We classified the results of FNAB as positive (including class C3, C4, C5) and negative (C2) adapted from Burapa Kanchanabat [11] and Etta D. Pisano [12]. C1 was temporarily exluded from this classification. Our reason for this classification is that solid masses with a FNAB result of intermediate classification $(\mathrm{C} 3, \mathrm{C} 4$,) require other diagnostic procedures to minimized the underestimation. 
Table 1 Summary of including studies (Insufficient Samples Excluded in test result)

\begin{tabular}{|c|c|c|c|c|c|c|c|c|}
\hline \multirow[t]{2}{*}{ study } & \multirow[t]{2}{*}{ year } & \multirow[t]{2}{*}{ reference standard } & \multicolumn{4}{|c|}{ test result } & \multirow[t]{2}{*}{ patients (number) } & \multirow[t]{2}{*}{ QUADAS score } \\
\hline & & & $\overline{T P}$ & FP & FN & $\mathrm{TN}$ & & \\
\hline Walker et al.[33] & 1998 & his & 91 & 0 & 0 & 19 & 110 & 13 \\
\hline Kanchanabat et al.[11] & 2000 & his/imag and clin & 8 & 8 & 0 & 26 & 42 & 10 \\
\hline Pisano et al.[12] & 2001 & his/imag and clin & 59 & 18 & 17 & 183 & 277 & 11 \\
\hline Lumachi et al.[34] & 1999 & his & 55 & 0 & 2 & 5 & 62 & 10 \\
\hline Farshid et al.[35] & 2008 & his/imag and clin & 91 & 120 & 2 & 880 & 1093 & 11 \\
\hline Dennison et al.[36] & 2003 & his/imag and clin & 95 & 0 & 10 & 38 & 143 & 10 \\
\hline Gent et al.[37] & 1986 & his & 39 & 7 & 1 & 109 & 156 & 13 \\
\hline Wanebo et al.[38] & 1983 & his & 123 & 8 & 1 & 102 & 234 & 13 \\
\hline Apesteguia et al.[39] & 1997 & his/imag and clin & 2 & 2 & 0 & 107 & 111 & 11 \\
\hline Manheimer et al.[40] & 1977 & his & 79 & 2 & 11 & 35 & 127 & 11 \\
\hline Janet et al.[41] & 2010 & his/imag and clin & 11 & 0 & 4 & 135 & 150 & 9 \\
\hline Drew et al.[42] & 1999 & his/imag and clin & 102 & 4 & 27 & 130 & 263 & 8 \\
\hline Masood et al.[43] & 1991 & his & 17 & 0 & 3 & 71 & 91 & 8 \\
\hline Ishikawa et al.[44] & 2007 & his & 138 & 4 & 4 & 178 & 324 & 12 \\
\hline Harvey et al.[45] & 1996 & his/imag and clin & 14 & 37 & 13 & 32 & 96 & 8 \\
\hline Leifland et al.[46] & 2003 & his & 353 & 11 & 52 & 27 & 443 & 11 \\
\hline Okamoto et al.[47] & 1998 & his/imag and clin & 5 & 1 & 1 & 125 & 132 & 11 \\
\hline Rubin et al.[48] & 1997 & his/imag and clin & 34 & 4 & 0 & 27 & 65 & 10 \\
\hline Sauer et al.[32] & 2003 & his/imag and clin & 360 & 21 & 47 & 321 & 749 & 11 \\
\hline Li et al.[49] & 2008 & his & 129 & 1 & 22 & 108 & 260 & 9 \\
\hline Wang et al.[50] & 2010 & his & 110 & 2 & 7 & 55 & 174 & 13 \\
\hline Yang et al.[51] & 2010 & his & 79 & 0 & 4 & 259 & 342 & 11 \\
\hline Liu et al.[52] & 2000 & his & 205 & 1 & 12 & 194 & 412 & 10 \\
\hline Zhao et al.[53] & 2009 & his & 218 & 10 & 6 & 241 & 475 & 11 \\
\hline Zhan et al.[54] & 2007 & his & 32 & 2 & 0 & 44 & 78 & 9 \\
\hline Gao et al.[55] & 2005 & his & 169 & 0 & 27 & 85 & 281 & 11 \\
\hline Lu et al.[56] & 2010 & his & 102 & 0 & 33 & 48 & 183 & 10 \\
\hline Liu et al.[57] & 2010 & his & 5 & 1 & 1 & 125 & 132 & 11 \\
\hline Zhang et al.[58] & 2008 & his & 39 & 6 & 4 & 53 & 102 & 11 \\
\hline Zhang et al.[59] & 2006 & his & 21 & 2 & 3 & 31 & 57 & 9 \\
\hline Tang et al.[60] & 1987 & his & 144 & 2 & 13 & 144 & 303 & 11 \\
\hline Wang et al.[61] & 1995 & his & 25 & 0 & 2 & 22 & 49 & 10 \\
\hline Ma et al.[62] & 2010 & his & 56 & 0 & 2 & 99 & 157 & 8 \\
\hline Wang et al.[63] & 2010 & his & 96 & 12 & 4 & 498 & 610 & 8 \\
\hline Wang et al.[64] & 1981 & his & 442 & 43 & 60 & 479 & 1024 & 10 \\
\hline Wei et al.[65] & 2007 & his & 91 & 4 & 2 & 78 & 175 & 12 \\
\hline Tao et al.[66] & 2004 & his & 655 & 5 & 14 & 2027 & 2701 & 12 \\
\hline Wang et al.[67] & 2005 & his & 99 & 5 & 0 & 207 & 311 & 11 \\
\hline Chen et al.[68] & 2010 & his & 66 & 1 & 9 & 176 & 252 & 8 \\
\hline Zeng et al.[69] & 1999 & his & 94 & 1 & 2 & 66 & 163 & 11 \\
\hline Jia et al.[70] & 1986 & his & 49 & 0 & 1 & 50 & 100 & 9 \\
\hline Ma et al.[71] & 2010 & his & 68 & 0 & 4 & 291 & 363 & 10 \\
\hline Huang et al.[72] & 2003 & his & 305 & 31 & 54 & 436 & 826 & 11 \\
\hline Zhang et al.[73] & 1996 & his & 21 & 1 & 2 & 40 & 64 & 9 \\
\hline Yu et al.[74] & 2006 & his & 1620 & 116 & 33 & 359 & 2128 & 11 \\
\hline Jiang et al.[75] & 2008 & his & 66 & 1 & 9 & 176 & 252 & 11 \\
\hline
\end{tabular}

His: histopathology; imag and clin:imaging and clinical follow-up; TP:true positive; FP: false positive; FN:false negative; TN: true negative. 
The following measures of test accuracy were computed for each study: sensitivity; specificity; diagnostic odds ratio (DOR); positive likelihood ratio (PLR) and negative likelihood ratio (NLR). As for unsatisfactory samples (C1), it includes disfigured cellular morphology that cannot be interpreted and fewer than five epithelial cell groups. Disputes about unsatisfactory samples were among these studies on account of following therapeutic decisions. In most of the studies, unsatisfactory samples were excluded from analysis while considered to be positive in a study [12]. Since unsatisfactory samples played important roles on therapeutic decisions, we also assessed the sensitivity and specificity for the studies which reported unsatisfactory samples (unsatisfactory samples considered to be positive in our classification) and underestimation rate of unsatisfactory samples.

The analysis was based on a summary receiver operating characteristic (SROC) curve $[13,14]$. Sensitivity and specificity for the single test threshold identified for each study were used to plot an SROC curve. Random-effects model was used to calculate the average sensitivity, specificity, and the other measures across studies [15].

The term heterogeneity when used in relation to metaanalyses refers to the degree of variability in results across studies. We used the X2 and Fisher exact tests to detect statistically significant heterogeneity. To assess the effects of QUADAS scores on the diagnostic ability of FNAB, we included it as covariates in univariate meta-regression analysis (inverse variance weighted). We also analyzed the effects of other covariates on DOR (ie, publication year, guidance systems, 21 or other size needle gauge, different reference standard, prospective data collection, and different geographic location). The relative DOR (RDOR) was calculated according to standard methods to analyze the change in diagnostic precision in the study per unit increase in the covariate $[16,17]$. Since publication bias is of concern for meta-analyses of diagnostic studies, we tested for the potential presence of this bias using funnel plots [18].

\section{Results}

After independent review, 59 publications dealing FNAB for the diagnosis of breast cancer were considered to be eligible for inclusion in the analysis. Of these publications, eight studies [19-26] were excluded because FNAB was performed only in breast cancer patients, two studies $[27,28]$ were excluded because they evaluated the role of FNAB in diagnosis of axillary lymph nodes, two studies $[29,30]$ were excluded because they did not allow the calculation of sensitivity or specificity or underestimate rate, one studies [31] were excluded because its data had been included as a part of the latest study [32]. Subsequently, 46 studies [11,12,32-75] including 7207 patients with breast cancer or suspicious features and 9435 patients with benign mass were available for analysis, and the clinical characteristics of these studies, along with QUADAS scores, are outlined in Table 1. In addition, we derived relative data about unsatisfactory samples from $11[11,12,32,33,35,37-39,44,46,50]$ studies in table 2.

\section{Study characteristics and quality of studies}

As shown in Table 1 and Table 3 the average sample size of the included studies was 362 patients (range, 42 to 2128). Twenty-night studies were performed in Asia; Seventeen studies were conducted in NA (Canada and USA) and Europe. With the exception of one study which was multicenter [12], the others were single center. Most studies were case series (41 retrospective, 5 prospective).

The age of patients ranged from 26 to 87 years. Risk factors for cancer in the selected population, i.e., family history, genetic predisposition, menopausal status, and/or prior high risk lesions, were rarely reported. Needle size has varied from 20 to 25 gauge in these studies, 15 studies used 21-gauge size while the others used 20, 22, 23, 25 size or didn't mentioned it. Four studies used stereotactic guidance systems; five studies used ultrasound systems; four studies used stereotactic or ultrasound guidance systems according to the breast mass; the rest studies performed FNAB without any kind of imaged guidance systems. Two outcome measurements were adopted by these studies. As histopathologic results from surgical biopsy was regarded as gold standard in this field, patients with malignant lesions, cells suspicious, or when requested, subsequently underwent open surgery in all these studies. In case of benign lesions (breast cysts and a benign cytological result from low-risk patients), clinical and imaged follow-up at least 6 months was adopted by some studies while most of the studies still have involved

Table 2 Test result of studies (Insufficient Samples Classified as Positive)

\begin{tabular}{lccccc}
\hline study & \multicolumn{4}{c}{ test result } & \multirow{2}{*}{ Patients number } \\
\cline { 2 - 5 } & TP & FP & FN & TN & \\
\hline Walker et al.[33] & 95 & 11 & 0 & 19 & 125 \\
Kanchanabat et al.[11] & 8 & 13 & 0 & 26 & 47 \\
Pisano et al.[12] & 80 & 149 & 17 & 183 & 429 \\
Farshid et al.[35] & 92 & 173 & 2 & 880 & 1147 \\
Gent et al.[37] & 39 & 38 & 1 & 109 & 187 \\
Wanebo et al.[38] & 135 & 18 & 1 & 102 & 256 \\
Apesteguia et al.[39] & 2 & 36 & 0 & 107 & 145 \\
Ishikawa et al.[44] & 156 & 44 & 4 & 178 & 382 \\
Leifland et al.[46] & 406 & 37 & 52 & 27 & 522 \\
Sauer et al.[32] & 382 & 82 & 47 & 321 & 832 \\
Wang et al.[50] & 119 & 5 & 7 & 55 & 186 \\
\hline
\end{tabular}

TP:true positive; FP: false positive; FN:false negative; TN: true negative. 
Table 3 characteristics of studies

\begin{tabular}{|c|c|c|c|c|c|}
\hline study & $\begin{array}{l}\text { study design } \\
\text { prospective }\end{array}$ & $\begin{array}{l}\text { geographic location } \\
\text { Asia }\end{array}$ & $\begin{array}{l}21 \text { needle } \\
\text { gauge }\end{array}$ & $\begin{array}{l}\text { Apply imaging guidance } \\
\text { systems }\end{array}$ & $\begin{array}{l}\text { histopathology standard } \\
\text { only }\end{array}$ \\
\hline Walker et al.[33] & yes & no & yes & no & Yes \\
\hline $\begin{array}{l}\text { Kanchanabat et al. } \\
{[11]}\end{array}$ & yes & yes & no & no & no \\
\hline Pisano et al.[12] & yes & no & no & yes & no \\
\hline Lumachi et al.[34] & no & no & not mention & yes & yes \\
\hline Farshid et al.[35] & yes & no & not mention & no & no \\
\hline Dennison et al.[36] & yes & no & yes & no & no \\
\hline Gent et al.[37] & no & no & no & yes & yes \\
\hline Wanebo et al.[38] & no & no & no & yes & yes \\
\hline $\begin{array}{l}\text { Apesteguia et al. } \\
\text { [39] }\end{array}$ & no & no & no & yes & no \\
\hline $\begin{array}{l}\text { Manheimer et al. } \\
{[40]}\end{array}$ & no & no & no & no & yes \\
\hline Janet et al.[41] & no & yes & no & no & no \\
\hline Drew et al.[42] & no & no & not mention & no & no \\
\hline Masood et al.[43] & no & no & not mention & no & yes \\
\hline Ishikawa et al.[44] & no & yes & no & no & yes \\
\hline Harvey et al.[45] & no & no & not mention & yes & no \\
\hline Leifland et al.[46] & no & no & yes & yes & yes \\
\hline Okamoto et al.[47] & no & yes & yes & yes & no \\
\hline Rubin et al.[48] & no & no & not mention & no & no \\
\hline Sauer et al.[32] & no & no & not mention & yes & no \\
\hline Li et al.[49] & no & yes & not mention & no & yes \\
\hline Wang et al.[50] & no & yes & not mention & no & yes \\
\hline Yang et al.[51] & no & yes & not mention & no & yes \\
\hline Liu et al.[52] & no & yes & not mention & no & yes \\
\hline Zhao et al.[53] & no & yes & yes & no & yes \\
\hline Zhan et al.[54] & no & yes & yes & no & yes \\
\hline Gao et al.[55] & no & yes & yes & no & yes \\
\hline Lu et al.[56] & no & yes & no & yes & yes \\
\hline Liu et al.[57] & no & yes & yes & yes & yes \\
\hline Zhang et al.[58] & no & yes & no & no & yes \\
\hline Zhang et al.[59] & no & yes & yes & yes & yes \\
\hline Tang et al.[60] & no & yes & yes & no & yes \\
\hline Wang et al.[61] & no & yes & no & yes & yes \\
\hline Ma et al.[62] & no & yes & no & no & yes \\
\hline Wang et al.[63] & no & yes & no & no & yes \\
\hline Wang et al.[64] & no & yes & yes & no & yes \\
\hline Wei et al.[65] & no & yes & yes & no & yes \\
\hline Tao et al.[66] & no & yes & no & no & yes \\
\hline Wang et al.[67] & no & yes & yes & no & yes \\
\hline Chen et al.[68] & no & yes & yes & no & yes \\
\hline Zeng et al.[69] & no & yes & no & no & yes \\
\hline Jia et al.[70] & no & yes & yes & no & yes \\
\hline Ma et al.[71] & no & yes & no & no & yes \\
\hline Huang et al.[72] & no & yes & yes & no & yes \\
\hline Zhang et al.[73] & no & yes & yes & no & yes \\
\hline Yu et al.[74] & no & yes & yes & no & yes \\
\hline Jiang et al.[75] & no & yes & yes & no & yes \\
\hline
\end{tabular}


comparison of FNAB benign findings with histopathologic results from core-needle biopsy or open surgical biopsy.

We assessed the quality of the studies using QUADAS. Out of 14 QUADAS items, item 1 (spectrum composition) and item 2 (selection criteria) are about the variability of studies, item 8 (index test execution), 9 (reference standard execution) and 13 (uninterpretable test results) are about the quality of reporting, the rest of the items are about the bias of studies. If criterion was fulfilled, the item was signed "yes"; if not, the item was signed "no"; if study did not report clearly and we could not request the information from the authors, the item was signed "unknown". As shown in Table 4, item 1 and 2 were 91\% and 100\% fulfilled by studies respectively; item $8,9,13$ were $80 \%$, $100 \%, 24 \%$; in the rest of the items assessed bias reached a high level, except item 11 (reference standard review bias) and 14 (withdrawals).

\section{Diagnostic accuracy}

Figure 1 shows the forest plot of sensitivity and specificity for FNAB in the diagnosis of breast cancer ( $\mathrm{C} 1$ was temporarily exluded). The sensitivity ranged from 0.52 to 1.00 (mean, 0.927; 95\% confidence interval [CI], 0.921 to 0.933 ), and specificity ranged from 0.46 to 1.00 (mean, 0.948 ; $95 \%$ CI, 0.943 to 0.952 ). We also noted that PLR was 25.72 (95\% CI, 17.35 to 28.13), NLR was 0.08 (95\% CI, 0.06 to 0.11 ), and DOR was 429.73 (95\% CI, 241.75 to 763.87). X2 values of sensitivity, specificity, PLR, NLR, and DOR were 437.15 ( $\mathrm{p}<0.001), 840.00$ ( $\mathrm{p}<0.001)$, $653.52(\mathrm{p}<0.001), 464.80(\mathrm{p}<0.001)$, and $396.91(\mathrm{p}<$ 0.001 , respectively, with all indicating a significant heterogeneity between studies.

The SROC curve presents a global summary of test performance, and shows the tradeoff between sensitivity and specificity. A graph of the SROC curve for the biopsy results of FNAB (C1 was temporarily exluded) showing true-positive rates vs false-positive rates from individual studies is shown in Figure 2. Our data showed that the SROC curve is positioned near the desirable upper left corner of the SROC curve, and that the maximum joint sensitivity and specificity (ie, the Q-value) was 0.948 ; while the area under the curve (AUC) was 0.986, indicating a high level of overall accuracy.
Since unsatisfactory samples played important roles on therapeutic decisions, we assessed the pooled sensitivity and specificity for FNAB in the diagnosis of breast cancer in these 11 studies [11,12,32,33,35,37-39,44,46,50], which reported unsatisfactory samples (C1 was considered to be positive in this classification). As Figure 3 shows, the pooled sensitivity and specificity for this group were 0.920 (95\% CI, 0.906 to 0.933 ; X2 = 71.53, $\mathrm{p}<0.001)$ and 0.768 (95\% CI, 0.751 to $0.784 ; \mathrm{X} 2=$ 163.02, $\mathrm{p}<0.001)$ respectively. This graph of the SROC curve is shown in Figure 4. The maximum joint sensitivity and specificity was 0.815 ; while the area under the curve (AUC) was 0.884. In addition, we calculated and displayed the underestimation rates of unsatisfactory samples between FNAB and histopathologic standard in table 5. The pooled proportion of these unsatisfactory samples that were subsequently upgraded to various grade cancers was $27.5 \%$ (95\% CI, 0.221 to 0.296 ), X2 values was 159.85 ( $\mathrm{p}<0.001)$. This $\mathrm{p}$-values also indicated significant heterogeneity between studies.

\section{Multiple regression analysis and publication bias}

We used meta-regression to assess the different aspects among 46 studies: with or without 21-gauge, with or without imaging guidance systems, standard reference adopted histopathology only, located in Asia, prospective designs and QUADAS scores. Quality scoring was done by the use of QUADAS [76], in which a score of 1 was given when a criterion was fulfilled, 0 if a criterion was unclear, and -1 if the criterion was not achieved. As was shown in table 1 , the studies were with relative high quality if its score was more than ten. These scores were used in the meta-regression analysis to assess the effect of study quality on the RDOR of FNAB in the diagnosis of breast mass. The table 6 showed that excepted two aspects (with or without imaging guidance systems, standard reference adopted histopathology only), the rest aspects mentioned above did not substantially affect the diagnostic accuracy as their differences did not reach statistical significance ( $p>0.05)$.

The funnel plots for publication bias (Figure 5) showed large asymmetry. These results indicated a potential for publication bias.

Table 4 methodological quality of 46 studies

\begin{tabular}{|c|c|c|c|c|c|c|c|c|c|c|c|c|c|c|}
\hline & \multicolumn{14}{|c|}{ QUADAS item } \\
\hline & 1 & 2 & 3 & 4 & 5 & 6 & 7 & 8 & 9 & 10 & 11 & 12 & 13 & 14 \\
\hline Yes(n) & 42 & 46 & 46 & 40 & 46 & 35 & 46 & 37 & 46 & 46 & 7 & 39 & 11 & 13 \\
\hline $\mathrm{No}(\mathrm{n})$ & 4 & 0 & 0 & 0 & 0 & 11 & 0 & 5 & 0 & 0 & 0 & 0 & 0 & 3 \\
\hline Unknown(n) & 0 & 0 & 0 & 6 & 0 & 0 & 0 & 4 & 0 & 0 & 39 & 7 & 35 & 30 \\
\hline Yes(\%) & 91 & 100 & 100 & 87 & 100 & 76 & 100 & 80 & 100 & 100 & 15 & 85 & 24 & 28 \\
\hline
\end{tabular}

$\mathrm{n}$ : number of studies 

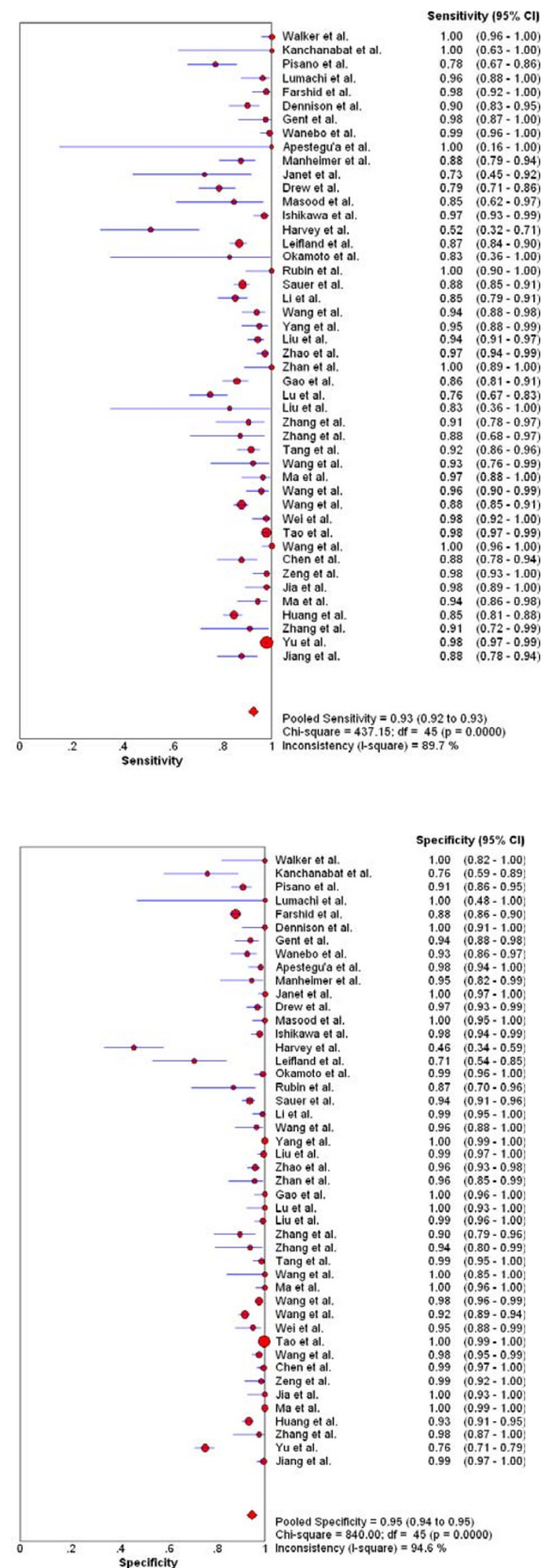

Figure 1 Forest plot of estimates of sensitivity and specificity for FNAB (C1 was temporarily exluded) in the diagnosis of breast cancer. The point estimates of sensitivity and specificity from each study are shown as solid circles. Error bars are $95 \%$ confidence intervals. The authors' names indicate the studies. 


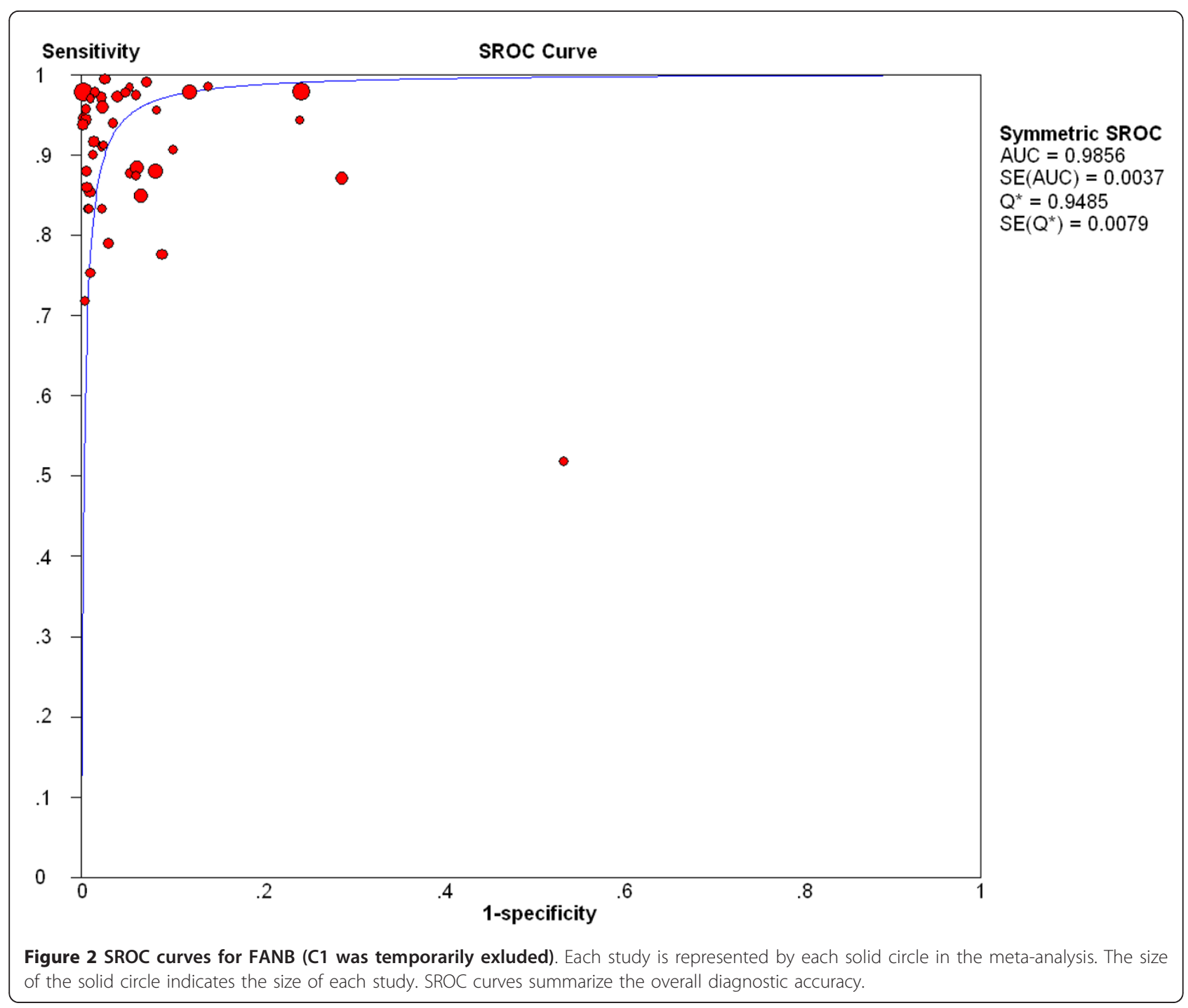

\section{Discussion}

Our current meta-analysis presented the high level diagnostic accuracy of Fine-needle aspiration biopsy (FNAB). In our first classification (C1 was temporarily exluded as most studies did.), the sensitivity rate was $92.7 \%$ and the specified rate was nearly $94.8 \%$. The SROC curve showed the maximum joint sensitivity and specificity (i.e. the Q-value) was 0.948 ; while the area under the curve (AUC) was 0.986, presenting excellent level of overall accuracy.

The DOR is a single indicator of test accuracy [77] that combines the data from sensitivity and specificity into a single number. The DOR of a test is the ratio of the odds of positive test results in the patient with disease relative to the odds of positive test results in the patient without disease. The value of a DOR ranges from 0 to infinity, with higher values indicating better discriminatory test performance (i.e. higher accuracy). A DOR of 1.0 indicates that a test does not discriminate between patients with the disorder and those without it. In the present meta-analysis, we have found that the mean DOR was 429.73, also indicating a high level of overall accuracy.

Since the SROC curve and the DOR are not easy to interpret and use in clinical practice, and since likelihood ratios are considered to be more clinically meaningful $[78,79]$, we also presented both PLR and NLR as our measures of diagnostic accuracy. Likelihood ratios of $>$ 10 or $<0.1$ generate large and often conclusive shifts from pre-test to post-test probability (indicating high accuracy) [79]. In our first classification, PLR value of 25.72 suggests that patients with various grade cancers have an approximately 26 -fold higher chance of being FNAB result-positive compared with patients with benign breast lesion. This high probability would be considered high enough to begin surgical treatment or other therapy. On the other hand, NLR was found to be 0.08 in our 




current meta-analysis. If the FNAB result was negative, the probability that this patient has breast carcinoma is approximately $8 \%$.

It should be emphasized that we used the approach of Burapa Kanchanabat [11] and Etta D. Pisano [12] for evaluating the diagnostic performance of FNAB (1. unsatisfactory samples was temporarily excluded; 2 . unsatisfactory samples was classified as positive). In our first classification, unsatisfactory samples (C1) was exluded as most studies did. In our second classification, 


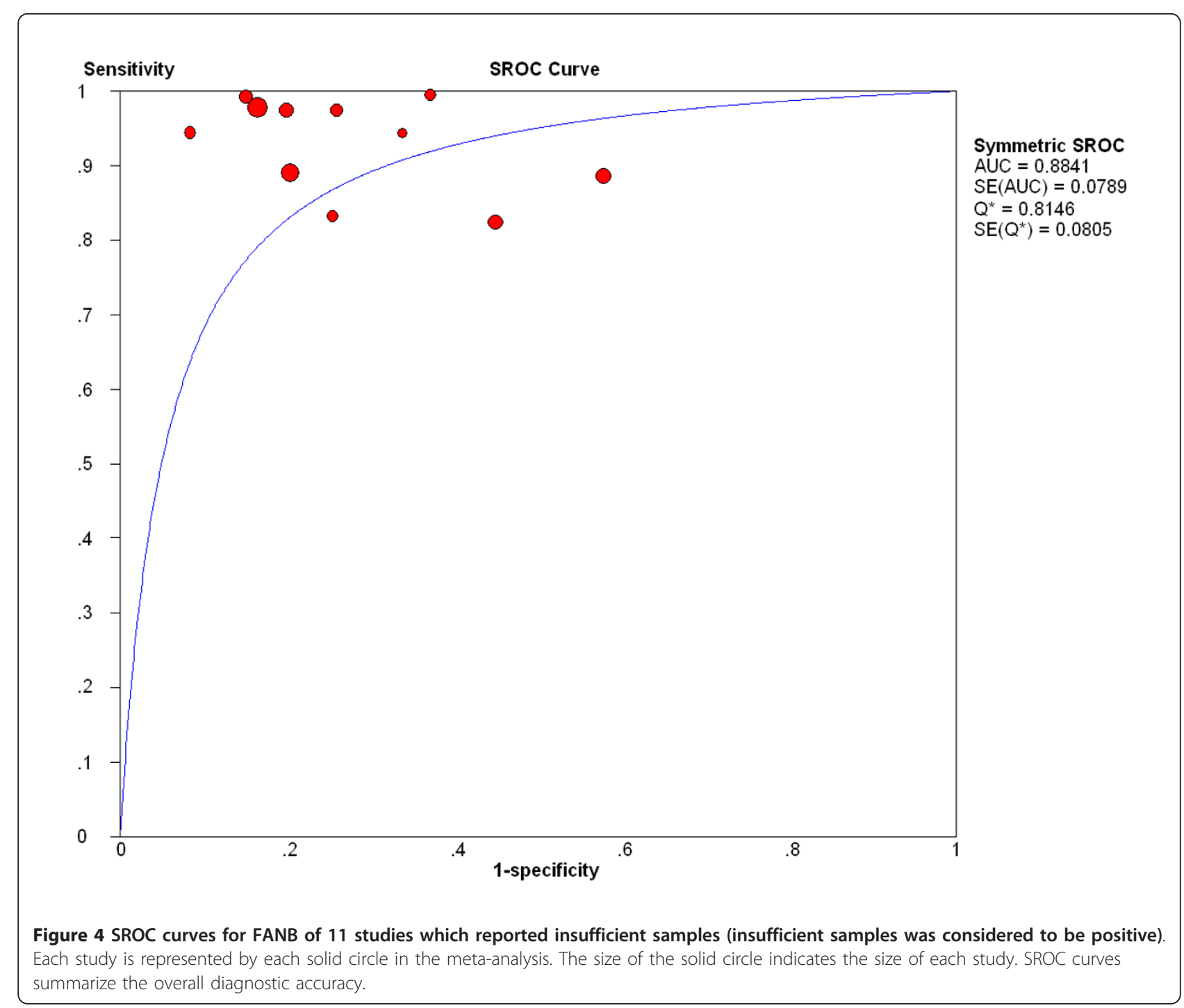

Inadequate cytological material have to be interpreted as "positive". Because treating the unsatisfactory result as a negative outcome is a poor policy that has the potential to cause harm to patients and delay the diagnosis of breast cancer. On the purpose of minimizing the chance of a missed diagnosis of breast cancer, certain discrepancies between FNAB and open biopsy (e.g. cytological results including $\mathrm{C} 3, \mathrm{C} 4, \mathrm{C} 5$ on FNAB and atypical hyperplasia or various grades cancer on open biopsy) were considered as agreements and needed further management. The reclassified agreement rate is therefore a clinically relevant and pragmatic estimate for the accordance between FNAB and actual disease status.
Breast cancer was present in certain proportion of the inadequate FNAB specimens. Since unsatisfactory samples (C1) played important roles in influencing diagnostic accuracy of FNAB, we also assessed the pooled sensitivity and specificity for FNAB in the other classification (unsatisfactory samples were regarded as positive) and the underestimation rate of unsatisfactory samples. This pooled sensitivity (92.7\%) was similar with the sensitivity $(92.0 \%)$ that mentioned above in our first classification (unsatisfactory samples was exluded) while the pooled specificity (76.8\%) was lower than the specificity (94.8\%) above. This change may be due to the underestimation rate of inadequate samples which was currently

Table 5 Summary underestimation rate of unsatisfactory samples using meta-analysis

\begin{tabular}{cccccccc}
\hline & $\mathbf{n}$ & $\mathbf{a}$ & $\mathbf{b}$ & pooled under-estimation rate & $\mathbf{9 5 \% C l}$ & $\mathbf{X}^{\mathbf{2}}$ & $\mathbf{P}$-value \\
\hline unsatisfactory Samples & 11 & 140 & 545 & $25.7 \%$ & $0.221-0.296$ & 159.85 & $\mathrm{p}<0.001$ \\
\hline
\end{tabular}

$\mathrm{n}=$ number of studies; $\mathrm{a}=$ number of breast cancer or Low grade cancers; $\mathrm{b}=$ total number of unsatisfactory Samples; 
Table 6 meta-regression of the effects of six different studies' aspects on diagnosis value of FNAB

\begin{tabular}{cccccc}
\hline Covariates & Number of studies & Coefficient & RDOR & 95\%Cl & P-value \\
\hline QUADAS $\geq 10$ & 34 & 0.747 & 2.11 & $0.60-7.47$ & 0.2389 \\
21-gauge & 19 & -0.705 & 0.49 & $0.16-1.53$ & 0.2149 \\
imaging guidance systems & 13 & -1.383 & 0.25 & $0.07-0.95$ & 0.0417 \\
histopathology only & 35 & 1.705 & 5.5 & $1.04-29.08$ & 0.0451 \\
prospective & 5 & 0.74 & 2.1 & $0.25-17.36$ & 0.4829 \\
Asia & 31 & 0.433 & 1.56 & $0.33-7.43$ & 0.5696 \\
\hline
\end{tabular}

assessed in our study. This pooled unsatisfactory samples' underestimate rate was $27.5 \%$ which was higher than the value $(8.5 \%)$ reported by H.C.Lee [80]. However, we included more recent related studies and more patients than H.C.Lee did. Our underestimate rate indicated that $27.5 \%$ of the patients with a diagnosis of inadequate samples for cytological analysis will prove to have various grades breast cancer. This rate was not low enough to rule out breast cancer. So, in most of these cases, an additional managemant such as core biopsies or surgical procedure will then be necessary.

On the whole, the quality of the included studies is higher than median level according to QUADAS. Many studies did not reach item 11 (reference standard review bias), 13 (uninterpretable test results) or 14 (withdrawals). According to QUADAS items and studies' detail analysis, most studies did not mention blinding results interpreted, uninterpretable test results or explained withdrawals which did not match item 11, 13 and 14. These bias would affect the analysis of accuracy of FNAB.

An exploration of the reasons for heterogeneity rather than the computation of a single summary measure was an important goal of meta-analysis [81]. In our metaanalysis, QUADAS scores were used in the meta-regression analysis to assess the effect of study quality on RDOR. We did not observe that the studies with relatively higher quality (QUADAS score of $\geq 10$ ) had better test performances than those with lower quality.

Although we found a significant heterogeneity for sensitivity, specificity, PLR, NLR and DOR among the studies analyzed, meta-regression results showed that 3 different aspects among 46 studies (such as needle size, study locations and prospective/retrospective designs) didn't reach statistical significance, indicating that these

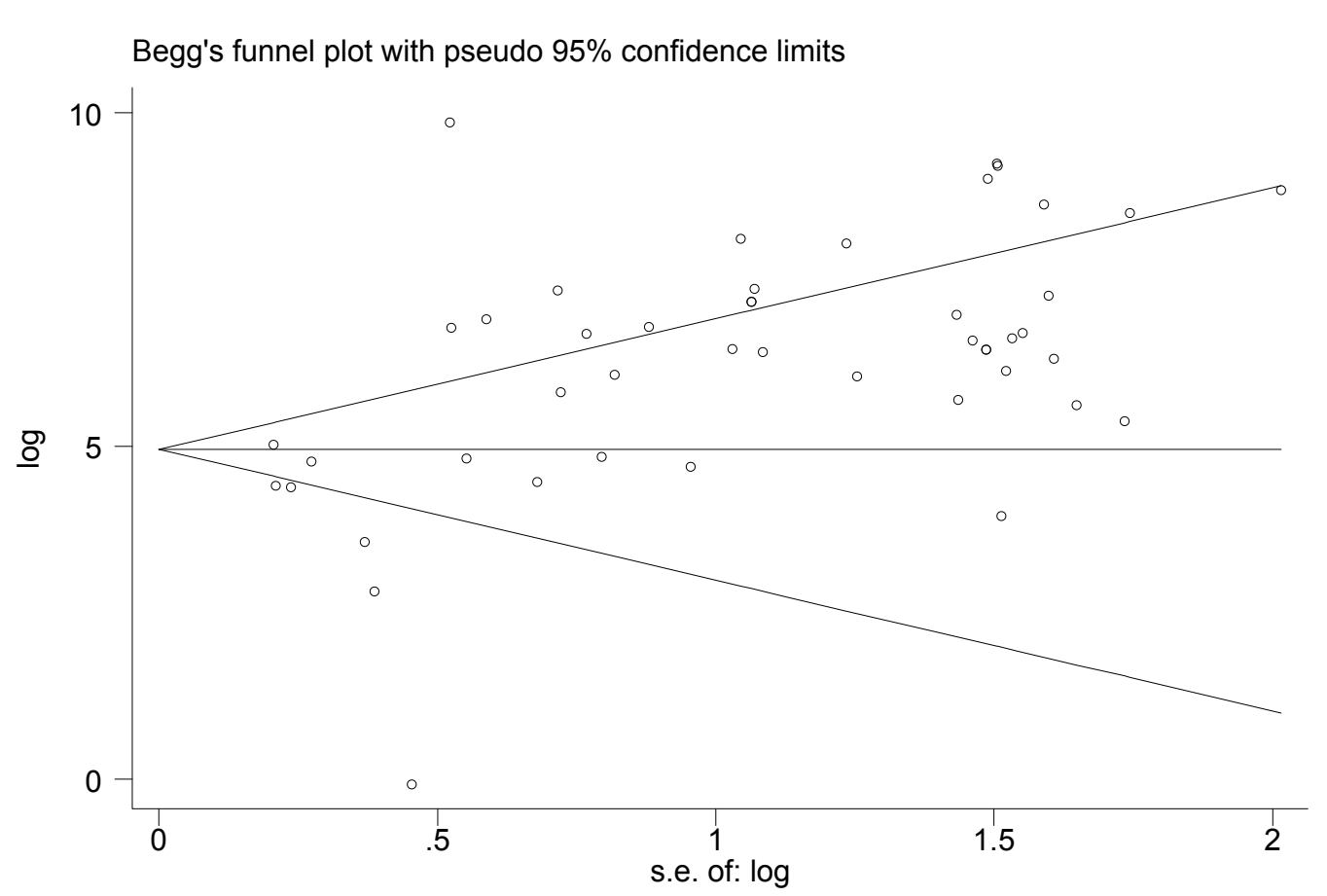

Figure 5 Funnel graph for the assessment of potential publication bias in FNAB. The funnel graph plots the log of the DOR against the SE of the log of the DOR (an indicator of sample size). Forty-six circle represents forty-six studies in the meta-analysis. The line in the centre indicates the summary diagnostic odds ratio. 
aspects did not substantially affect diagnostic accuracy. On the other hand, 2 different aspects such as guidance systems (with ultrasound or stereotactic guidance vs without imaging guidance) and reference standard (histopathology only or not) affect the diagnostic accuracy in great part. These may be due to the following reasons. First, fine-needle aspiration biopsy without imaging guidance is not suitable for patients with ill-defined masses because the aspiration cannot be done at the exact position and the cytological result may not represent the true nature of the mass. In other words, breast lesions could be definitely localized by imaging guidance then FNAB could be done. FNAB with imaging guidance system can make a favorite diagnosic accuracy. Second, there were the combined two standard methods adopted by some included studies, surgery biopsy for suspicious lesion and imaging or clinic follow-up for benign cytological result from low-risk patients. Moreover, the time of follow-up is different from each other (range from 6-24 months). As a result, misclassification may occur easier in this two different reference standard situation than in that histopathologic is the only reference standard.

Apart for having a comprehensive search strategy, our study assessed the FNAB diagnosis accuracy in all directions, such as sensitivity, specificity, PLR, NLR, DOR, SROC curve and AUC. In addition, we assessed the influence of unsatisfactory samples on FNAB diagnosis accuracy. Heterogeneity and potential publication bias were also explored in accordance with published guidelines. However, our systematic review had some limitations. Only including English and Chinese language studies and the lack of conference abstracts, letters to editors might have led to publication bias.

\section{Conclusion}

On the whole, our current evidence shows that fine-needle aspiration biopsy (FNAB) is an accurate biopsy for evaluating breast malignancy if rigorous criteria are used. With high sensitivity and specificity, most benign and malignant breast lesions can be reliably diagnosed by FNAB. FNAB may provide a favorable screening method and permit an improvement of treatment planning. With the introduction of imaging guided methods for percutaneous sampling of nonpalpable lesions, FNAB can be used more widely in the evaluation of breast lesions

However, as unsatisfactory samples' underestimate rate $(27.5 \%)$ is not low enough to rule out malignant, the result of $\mathrm{C} 1$ for cytological analysis in FNAB warrants futher invasive procedures including core biopsies or open surgical biopsy in order to minimize the chance of missed diagnosis of breast cancer. Fine needle aspiration continues to be an acceptable and reliable procedure for the preoperative diagnosis of breast lesions, particularly in developing countries.

\section{Abbreviations}

FNAB: Fine-needle aspiration biopsy; His: histopathology; Imag and clin: clinical and imaging follow-up; AUC: area under the curve; Cl: confidence interval; DOR: diagnostic odds ratio; IFN: interferon; NLR: negative likelihood ratio; PLR: positive likelihood ratio; QUADAS: quality assessment for studies of diagnostic accuracy; RDOR: relative diagnostic odds ratio; ROC: receiver operating characteristic; SROC: summary receiver operating characteristic.

\section{Acknowledgements}

The authors wish to thank Guiqi Liang, Meizhen Lu, Junming Huang and Drs. Taixiang Wu for helpful discussions.

\section{Authors' contributions}

Jian Lun Liu conceived of the study. Ying Hua Yu was in charged of its design and coordination. Ying Hua Yu and Wei Wei performed the statistical collection and analysis. Ying Hua Yu drafted the manuscript. All authors read and approved the final manuscript.

\section{Competing interests}

The authors declare that they have no competing interests.

Received: 12 May 2011 Accepted: 25 January 2012

Published: 25 January 2012

\section{References}

1. Gupta RK, Naran S, Buchanan A, Fauck R, Simpson J: Fine-needle aspiration cytology of breast: its impact on surgical practice with an emphasis on the diagnosis of breast abnormalities in young women. Diagn Cytopathol 1988, 4:206-209.

2. Dowlatshahi $K$, Jokich PM, Schmidt R, Bibbo M, Dawson PJ: Cytologic diagnosis of occult breast lesions using stereotactic needle aspiration: a preliminary report. Arch Surg 1987, 122:1343-1346.

3. Evans WP, Cade SH: Needle localization and fine-needle aspiration biopsy of nonpalpable breast lesions with use of standard and stereotactic equipment. Radiology 1989, 173:53-56.

4. Sterrett G, Oliver D, Trayne J, Ingram D, Sherner H: Stereotactic fine-needle aspiration biopsy (SFNB) of breast: preliminary results in Perth with the TRC Mammotest machine-cytological aspects. Pathology 1991, 23:302-310.

5. Azavedo E, Svane G, Auer G: Stereotactic fine-needle biopsy in 2594 mammographically detected nonpalpable lesions. Lancet 1989, 1:1033-1035.

6. Evans WP, Cade SH: Needle localization and fine-needle aspiration biopsy of nonpalpable breast lesions with use of standard and stereotactic equipment. Radiology 1989, 173:53-56.

7. Jay H, Monica M, Marce L, Samuel H: Disease of the Breast. Philadelphia: Lippincott-Raven 1996, Ch. 5.

8. Jackson VP, Reynolds HE: Stereotactic needle-core biopsy and fine-needle aspiration cytologic evaluation of nonpalpable breast lesions. Radiology 1991, 181:633-634.

9. Whiting PF, Weswood ME, Rutjes AWS, Reitsma JB, Bossuyt PNM, Kleijnen J: Evaluation of QUADAS, a tool for the quality assessment of diagnostic accuracy studies. BMC Medical Research Methodology 2006, 6:9.

10. Deville WL, Buntinx F, Bouter LM, Montori VM, Vet HCW, Windt DAWM, Bezemer PD: Conducting systematic reviews of diagnostic studies: didactic guidelines. BMC Med Res Methodol 2002, 2:9.

11. Kanchanabat B, Kanchanapitak P, Thanapongsathorn W, Manomaiphiboon A: Fine-needle aspiration cytology for diagnosis and management of palpable breast mass. Aust NZ J Surg 2000, 70:791-794.

12. Pisano ED, Fajardo LL, Caudry DJ, Sneige N, Frable WJ, Berg WA, Tocino I, Schnitt SJ, Connolly JL, Gatsonis CA, McNeil BJ: Fine-Needle Aspiration Biopsy of Nonpalpable Breast Lesions in a Multicenter Clinical Trial: Results from the Radiologic Diagnostic Oncology Group V. Radiology 2001, 219:785-792.

13. Moses LE, Shapiro D, Littenberg B: Combining independent studies of a diagnostic test into a summary ROC curve: data-analytic approaches and some additional considerations. Stat Med 1993, 12:1293-1316.

14. Lau J, loannidis JP, Balk EM, Milch C, Terrin N, Chew PW, Salem D: Diagnosing acute cardiac ischemia in the emergency department: a systematic review of the accuracy and clinical effect of current technologies. Ann Emerg Med 2001, 37:453-460. 
15. Irwig L, Tosteson AN, Gatsonis C, Lau J, Colditz G, Chalmers TC, Mosteller F: Guidelines for meta-analyses evaluating diagnostic tests. Ann Intern Med 1994, 120:667-676.

16. Suzuki S, Moro-oka T, Choudhry NK: The conditional relative odds ratio provided less biased results for comparing diagnostic test accuracy in meta-analyses. J Clin Epidemiol 2004, 57:461-469.

17. Westwood ME, Whiting PF, Kleijnen J: How does study quality affect the results of a diagnostic meta-analysis? BMC Med Res Methodol 2005, 8:20.

18. Egger M, Davey Smith G, Schneider M, Minder C: Bias in meta-analysis detected by a simple, graphical test. BMJ 1997, 315:629-634.

19. Mezzelani A, Alasio L, Bartoli C, Bonoral MG, Pierotti MA, Rilke F, Pilotti S: CerbB2/neu gene and chromosome 17 analysis in breast cancer by FISH on archival cytological fine-needle aspirates. British Journal of Cancer 1999, 80:519-525.

20. Bofin AM, Ytterhus B, Hagmar BM: TOP2A and HER-2 gene amplification in fine needle aspirates from breast carcinomas. Cytopathology 2003, 14:314-319.

21. Somani A, Hwang JSG, Chaiwun B, Tse GMK, Liu PCWUI, Tan PH: Fine needle aspiration cytology in young women with breast cancer: diagnostic difficulties. Pathology 2008, 40(4):359-364.

22. Gazic B, Pizem J, Bracko M, Cufer T, Borstnar S, Pohar-Marinsek Z, UsKrasovec M: S-phase fraction determined on fine needle aspirates is an independent prognostic factor in breast cancer - a multivariate study of 770 patients. Cytopathology 2008, 19:294-302.

23. Kelten C, Akbulut M, Zekioglu O, Kapkac M, Erhan Y, Ozdemir N: Signet ring cells in fine needle aspiration cytology of breast carcinomas: review of the cytological findings in ten cases identified by histology. Cytopathology 2009, 20:321-327.

24. Zhang BL, Chang LX: Comparison Between Serum Cancer Antigen 15. 3 Diagnosing Mammary Cancer and Fine Needle Aspination Cytology Diagnosing Mammary Cancer. J PMT 2006, 13:1235-1236.

25. Sun YF, Xu JH, Ye K, Xu ST: The value of preoperative diagnosis based on fine - needle aspiration cytology for breast cancer. Hebei Medicine 2010, 16(3):300-302.

26. Jin WH, Li RY, Cui CA, Piao DM, Shen ZS: Diagnostic value of fine needle aspiration biopsy telomerase activity in breast neoplasm. CHIN J CANCER PREV TREAT 2004, 11(5):485-487.

27. Sapino A, Cassoni P, Zanon E, Fraire F, Croce S, Coluccia C, Donadio M, Bussolati G: Ultrasonographically-guided fine-needle aspiration of axillary lymph nodes: role in breast cancer management. British Journal of Cancer 2003, 88:702-706.

28. Jain A, Haisfield-Wolfe ME, Lange J, Ahuja N, Khouri N, Tsangaris T, Zhang Z, Balch C, Jacobs LK: The Role of Ultrasound-Guided Fine-Needle Aspiration of Axillary Nodes in the Staging of Breast Cancer. Annals of Surgical Oncology 2002, 15(2):462-471.

29. Kooistra B, Wauters C, Strobbe L: Indeterminate Breast Fine-Needle Aspiration: Repeat Aspiration or Core Needle Biopsy? Ann Surg Oncol 2009, 16:281-284.

30. Jeronimo G, Monteiro P, Henrique R, Dinis-Ribeiro M, Costa I, Costa VL, Filipe L, Carvalho A, Hoque MO, Pais I, Leal C, Teixeira MR, Sidransky D: Quantitative hypermethylation of a small panel of genes augments the diagnostic accuracy in fine-needle aspirate washings of breast lesions. Breast Cancer Res Treat 2008, 109:27-34.

31. Sauer $T$, Young $K$, Thoresen SS: Fine needle aspiration cytology in the work-up of mammographic and ultrasonographic finding in breast cancer screening: an attempt at differentiating in situ and invasive carcinoma. Cytopathology 2002, 13:101-110.

32. Sauer T, Myrvold K, LCmo J, Anderssen KY, Skaane P: Fine-needle aspiration cytology in nonpalpable mammographic abnormalities in breast cancer screening: results from the breast cancer screening programme in Oslo 1996-2001. The Breast 2003, 12:314-319.

33. Walker SR: A randomized controlled trial comparing a $21 \mathrm{G}$ needle with a $23 \mathrm{G}$ needle for fine needle aspiration of breast lumps. J $R$ Coll Surg Edink 1998, 43:322-332.

34. Lumachi F, Marzola MC, Zucchetta P, Polistina F, Cagnato P, Favia G, Bui F: Breast Cancer Detection With 99m-Tc-Sestamibi Scintigraphy, Mammography, and Fine-Needle Aspiration Cytology: Comparative Study in 64 Surgically Treated Patients. Annals of Surgical Oncology 1999, 6(6):568-571.

35. Farshid G, Downey P, Gill PG, Pieterse S: Assessment of 1183 screendetected, category $3 \mathrm{~B}$, circumscribed masses by cytology and core biopsy with long-term follow up data. British Journal of Cancer 2008, 98:1182-1190

36. Dennison G, Anand R, Makar SH, Pain JA: A Prospective Study of the Use of Fine-Needle Aspiration Cytology and Core Biopsy in the Diagnosis of Breast Cancer. The Breast Journal 2003, 9(4):491-493.

37. Gent HJ, Sprenger E, Doulatshahl K: Stereotaxic needle localization and cytological diagnosis of occult breast lesions. Ann Surg 1986, 204(5):580-584.

38. Wanebo HJ, Feldman PS, Wilhelm MC, Covell $J$, Binns RL: Fine needle aspiration cytology in lieu of oper biopsy in management of primary breast cancer. Ann Surg 1984, 199(5):570-579.

39. Apesteguia L, Pina L, Inchusta M, Mellado M, Franque T, Miguel DC, LopezCousillas A, Reparaz B: Nonpalpable, well-defined, probably benign breast nodule: management by fine-needle aspiration biopsy and long-interval follow-up mammography. Eur. Radiol 1997, 7:1235-1239.

40. Manheimer LH, Rywlin AM: Fine needle aspiration cytology. Southern medical journal 1977, 70(8):293-295.

41. Jan M, Mattoo JA, Salroo NA, Ahangar S: Triple assessment in the diagnosis of breast cancer in Kashmir. Indian J Surg 2010, 72:97-103.

42. Drew PJ, Turnbull LW, Chatterjee S, Read J, Carleton PJ, Fox JN, Monson JRT, Kerin MJ: Prospective Comparison of Standard Triple Assessment and Dynamic Magnetic Resonance Imaging of the Breast for the Evaluation of Symptomatic Breast Lesions. Annals of surgery 1999, 230(5):680-685.

43. Masood S, Frykberg ER, Mclellan GL, Bullard JB: Application of estrogen receptor immunocytochemical assay to aspirates from mammographically guided fine needle biopsy of nonpalpable breast lesions. Southern medical journal 1991, 84(7):857-861.

44. Ishikawa T, Hamaguchi Y, Tanabe M, Momiyama N, Chishima T, Nakatani Y, Nozawa A, Sasaki T, Kitamura H, Shimada H: False-Positive and FalseNegative Cases of Fine-Needle Aspiration Cytology for Palpable Breast Lesions. Breast Cancer 2007, 14(4):388-392.

45. Crotch-Harvey MA, Loughran CF: Combined stereotactic wide-core needle biopsy and fine-needle aspiration cytology in the assessment of impalpable mammographic abnormalities detected in a breastscreening programme. The Breast 1996, 5:48-49.

46. Leifland K, Lagersted U, Svane G: Comparison of stereotactic fine needle aspiration cytology and core needle biopsy in 522 non-palpable breast lesions. Acta Radiologica 2003, 44:387-391.

47. Okamoto H, Ogawara T, Inoue S, Kobayashi K, Sekikawa T, Matsumoto Y: Clinical Management of Nonpalpable or Small Breast Masses by FineNeedle Aspiration Biopsy (FNAB) Under Ultrasound Guidance. Journal of Surgical Oncology 1998, 67:246-250.

48. Rubin M, Horiuchi K, Joy N, Haun W, Read R, Ratzer E, Fenoglio M, Colorado D: Use of Fine Needle Aspiration for Solid Breast Lesions Is Accurate and Cost-Effective. The American journal of surgery 1997, 7:694-698.

49. Li JG: The value of CA15-3 and Fine-needle aspiration about the diagnosis of breast cancer. J of Radioimmunology 2008, 21(2):190-191.

50. Wang DJ: The value of the Fine-needle aspiration about the diagnosis and treatment of breast neoplasms (D). Fu Jian: Fujian Medical University 2010.

51. Yang $H Y$, Bao $L$ : Value of fine needle aspiration cytology in the diagnosis of breast cancer. Maternal and Child Health in China 2000, 25:1995-1996.

52. Liu CJ: Cytological diagnosis of breast cancer by fine needle aspiration: experience of 688 cases. Medicine Theory and Practice 2000, 13:436-437.

53. Zhao QW, Zhan Y, Yu XM, Guo QH: Value of fine needle a spiration biopsy in cytological diagnosis of breaet cancer. Journal of Xinxiang Medical College 2009, 26(5):481-483.

54. Zhan PY, Ye EBLT: The Cytology Result Analysis of Thin needle Puncture to 126 Cases Mammry Tumour. JPMT 2007, 14:435-436.

55. Gao L, Zhang MH, Zhu MH: Histopathology and fine needle aspiratory cytology of 281 cases of breast mass: a comparison analysis. Acad J Sec Mil Med Univ 2005, 26:825-826.

56. Lu B, Chen BX, Sun FX, Yan YJ, Wang LD: The value of ultrasound-guided fine needle aspiratory with continuous negative pressure in diagnosis of breast disease. Chin J of Clinical Rational Drug Use 2010, 3:106-107.

57. Liu QH, Hong J, Liu Y, Xu M: Application of Fine needle Aspiration Biopsy Under Ultrasonic Guidance in the Diagnosis of Breast Lesions. Journal of Mathematical Medicine 2010, 23:216-217. 
58. Zhang YA, Li JS, Ji ZL, Tang WH: Combined use of fine needle aspiration cytology and full field digital mammography in preoperative assessment of breast masses. Chinese-German Journal of Clinical Oncology 2008, 7:473-476.

59. Zhang YN, You CZ, Li JS, Chen WD, Fan X, Hu HL, Zheng KE, Liu WH, Hao YY, He J, Tang WH: The diagnostic value of digital mammography, ultrasonography and fine needle aspiration biopsy in breast cancer. ModernMedical Journal 2006, 34(6):392-394.

60. Tang SS, Qian WZ, Yao ZX, Nan WK, Tu TX, Lu YS, Zhang WY: Cytological diagnosis of breast disease by fine needle aspiration: experience of 464 cases. Si Chuan Medical Journal 1987, 8(5):278-279.

61. Wang $H$, Zhou Q, Zhang L, Pan YC, Pan WS: The value of stereotacticguided fine needle aspiratory in diagnosis of breast disease. Diagnostic Pathology Journal 1995, 2(5):29-31.

62. Ma JZ, Gan J, Wu D, Li N, Zhang JJ: Value of Fine needle aspiration in the diagnosis of breast mass. Journal of Qi qi ha er Medical College 2010, 13:1903.

63. Wang Y, Li J: Results analysis of 610 mammary gland tumors by using thin needle puncture cytolog. Modern medical and health Journal 2010, 26(7):1004-1005

64. Wang HF: Cytologic examination of breast mass with fine needle aspiration technique in 1024 cases. Oncology Supplement 1981, 139-140.

65. Wei LW, Han GX, Liu JB, Wei LM, Dong SY, Wang QB: The clinical value of fine needle aspiration cytologic diagnosis for breast masses. Journal of Tai Shan Medical College 2007, 28:41-43.

66. Tao GH, Liu ZF, Liu HM, Liu YQ, He AL, Guan TY: A Study of Fine Needle Aspiration Cytologic Diagnosis for Breast Masses. Henan Journal of oncology 2004, 17:350-351.

67. Wang PL, Hui JJ: A Study of 311 cases of physical examination combined with fine needle aspiration in the diagnosis of breast lumps. Journal of Practical Medical Techniques 2005, 12:1679-1680.

68. Chen TJ: A study of pathologic diagnosis of fine needle aspiration cytology in breast masses. China Prac Med 2010, 5:15-116.

69. Zeng $H$, Wang $Y$ : The value of fine needle aspiration cytology in the diagnosis of breast mass. Gui Zhou Medical Journal 1999, 23:260-261.

70. Jia ZG, Pan RQ: Analysis of 100 cases of fine needle aspiration cytology in the diagnosis of breast mass. Practical Surgery Journal 1986, 6:583-584.

71. Ma LA, Yang HY: Value of fine needle aspiration cytology in the diagnosis of breast mass. Maternal and Child Health in China 2010, 25:2147-2148

72. Huang YJ, Shu QJ: The role of fine needle aspiration cytology in the diagnosis of breast lesions. Oncology Journal 2003, 9:120-121.

73. Zhang GX, Yong DY: Cytological diagnosis of breast tumor by fine needle aspiration:experience of 64 cases. Journal of Shan Xi College of Traditional Chinese Medicine 1996, 19:19.

74. Yu KQ, Yang WQ, Yang JM: The role of fine needle aspiration cytology in the diagnosis of breast tumor. Shandong Medical Journal 2006, 46:70-71.

75. Jiang Y, Wang Q, Wang GY, Zhou LM, Lin TJ: The research of fine needle aspiration cytology in the diagnosis of breast tumor. Guang Zhou Medical Journal 2008, 39:44-45

76. Whiting P, Rutjes AW, Reitsma JB, Bossuyt PMM, Kleijnen J: The development of QUADAS: a tool for the quality assessment of studies of diagnostic accuracy included in systematic reviews. BMC Med Res Methodol 2003, 3:25.

77. Glas AS, Lijmer JG, Prins MH, Bonsel GJ, Bossuy PMM: The diagnostic odds ratio: a single indicator of test performance. J Clin Epidemiol 2003, 56:1129-1135

78. Deeks JJ: Systematic reviews of evaluations of diagnostic and screening tests. In Systematic reviews in health care: meta-analysis in context. Edited by: Egger M, Smith GD, Altman DG. London, UK: BMJ Publishing Group; 2001:248-282.

79. Jaeschke R, Guyatt G, Lijmer J: Diagnostic tests. In Users' guides to the medical literature: a manual for evidence-based clinical practice. Edited by: Guyatt G, Rennie D. Chicago, IL: AMA Press; 2002:121-140.

80. Lee HC, Ooi PJLL, Poh WT, Wong CY: Impact of inadequate fine-needle aspiration cytology on outcome of patients with papable breast lesions. Aust NZ J Surg 2000, 70:656-659.

81. Petitti DB: Approaches to heterogeneity in meta-analysis. Stat Med 2001, 20:3625-3633.

\section{Pre-publication history}

The pre-publication history for this paper can be accessed here: http://www.biomedcentral.com/1471-2407/12/41/prepub

doi:10.1186/1471-2407-12-41

Cite this article as: Yu et al.: Diagnostic value of fine-needle aspiration biopsy for breast mass: a systematic review and meta-analysis. BMC Cancer 2012 12:41.

\section{Submit your next manuscript to BioMed Central and take full advantage of:}

- Convenient online submission

- Thorough peer review

- No space constraints or color figure charges

- Immediate publication on acceptance

- Inclusion in PubMed, CAS, Scopus and Google Scholar

- Research which is freely available for redistribution

Submit your manuscript at www.biomedcentral.com/submit
Biomed Central 